\title{
RUANG BERNORMA LENGKAP ATAS OPERATOR LINEAR TERBATAS PADA RUANG FUNGSI TERINTEGRAL DUNFORD
}

\author{
Solikhin $^{1 *}$, YD Sumanto ${ }^{2}$, Abdul Aziz ${ }^{3}$, Susilo Hariyanto ${ }^{4}$, R. Heri \\ Soelistyo Utomo ${ }^{5}$ \\ 1,2,3,4,5 Departemen Matematika, Universitas Diponegoro \\ Email : ${ }^{1}$ solikhin, ${ }^{2}$ ydsumanto, ${ }^{3}$ abdulaziz, ${ }^{4}$ susilohariyanto, ${ }^{5}$ robertusherisoelisty[@lecturer.undip.ac.id] \\ ${ }^{*}$ Penulis Korespondensi
}

\begin{abstract}
We discuss the operator norm on space of Dunford integral function. We show that sets of all bounded linear operator from dual space of Banach space into space of Lebesgue integral function is Banach space.
\end{abstract}

Key word: Dunford integral, operator norms, Banach space.

\begin{abstract}
Abstrak. Artikel ini membahas norma operator atas operator linear terbatas pada ruang fungsi terintegral Dunford. Himpunan semua operator linear dari ruang dual atas ruang Banach ke ruang fungsi terintegral Lebesgue merupakan ruang bernorma yang lengkap terhadap norma operator yang diberikan.
\end{abstract}

Kata kunci: Integral Dunford, norma operator, ruang Banach.

\section{PENDAHULUAN}

Integral Dunford merupakan integral lemah suatu fungsi bernilai Banach $X$. Integral ini didefinisikan melalui fungsi terukur lemah. Jika diketahui bahwa fungsi $f$ terukur lemah, maka $f$ dikatakan terintegral Dunford jika untuk setiap $x^{*} \in X^{*}$ (dual dari $X$ ) komposisi fungsi bernilai riil $x^{*}(f)$ terintegral Lebesgue [1]. Artinya jika fungsi $f$ terintegral Dunford maka untuk setiap $x^{*} \in X^{*}, x^{*}(f)$ terintegral Lebesgue sebaliknya jika untuk setiap $x^{*} \in X^{*}$, $x^{*}(f)$ terintegral Lebesgue maka fungsi $f$ terintegral Dunford.

Kajian integral Dunford menjadi topik yang menarik bagi penulis dan beberapa peneliti lain. Integral Dunford juga digeneralisasi ke dalam integral tipe Riemann, yaitu integral Henstock-Dunford [2]. Kajian dalam tulisan ini adalah sifat-sifat dari integral HenstockDunford, teorema kekonvergenan, dan perluasan Harnack. Integral Henstock-Dunford juga diperluas ke dalam ruang Euclide [3].

Kajian dari integral Dunford tidak hanya dibahas sebatas teori integralnya tetapi juga operatornya. Dalam teori operator, khususnya operator adjoint dan operator kompak $[4,5]$ banyak digunakan dalam masalah matematika fisika, misalnya seperti mekanika kuantum. Operator adjoint sendiri digunakan untuk menyelesaikan persamaan integral yang mengandung operator. Telah dikaji operator pada ruang fungsi terintegral Dunford [6], operator Adjoint pada ruang fungsi terintegral Dunford dan operator linear kompak lemah pada ruang fungsi terintegral Dunford. 
Operator $T: X^{*} \rightarrow L_{1}$ yang bekerja pada ruang fungsi terintegral Dunford merupakan operator linear terbatas. Operator adjointnya $T^{*}: L_{1}^{*} \rightarrow X^{* *}$ juga bersifat linear terbatas [7]. Lebih lanjut, operator $T$ kompak lemah jika dan hanya jika operator adjoint $T^{*}$ kompak lemah [1].

Hasil kajian telah menunjukkan bahwa himpunan semua operator linear merupakan ruang linear, dimana operator linear tersebut didefinisikan dari ruang dual ke ruang fungsi terintegral Lebesgue. Lebih lanjut, terhadap suatu norma operator, yaitu fungsi yang didefinisikan pada ruang operator linear dan terbatas antara dua ruang linear yang diberi fungsi tersebut, merupakan ruang bernorma [8]. Melalui ruang bernorma ini, perlu dikaji apakah dengan norma operator yang telah didefinisikan bahwa ruang operator linear terbatas pada ruang fungsi terintegral Dunford tersebut lengkap.

\section{RUANG BERNORMA}

Diberikan definisi ruang bernorma beserta sifat-sifatnya dan barisan konvergen serta barisan Cauchy.

Definisi 2.1 [5] Diketahui himpunan $X$ adalah ruang linear. Fungsi $\|\cdot\|: X \rightarrow R$ dengan sifat :

(i). $\|x\| \geq 0$,

(ii). $\|x\|=0 \Leftrightarrow x=\theta$,

(iii). $\|u x\|=|u|\|x\|$, dan

(iv). $\|x+y\| \leq\|x\|+\|y\|$,

untuk setiap $x, y \in X$ dan sebarang skalar $u \in R$ dinamakan norma pada $X$.

Jika fungsi $\|\cdot\|$ merupakan norma pada $X$, maka pasangan $(X,\|\cdot\|)$ dinamakan ruang bernorma.

Definisi 2.2 [5] Diketahui $(X,\|\cdot\|)$ ruang bernorma. Barisan $\left(x_{n}\right) \subset X$ disebut konvergen jika ada $x \in X$ benar bahwa

$$
\lim _{n \rightarrow \infty}\left\|x_{n}-x\right\|=0 \text {. }
$$

Definisi 2.3 Diketahui ruang bernorma $(X,\|\cdot\|)$. Barisan $\left(x_{n}\right) \subset X$ disebut barisan Cauchy jika untuk setiap $\varepsilon>0$ ada bilangan asli $n_{0}$ sehingga untuk setiap bilangan asli $n, m \geq n_{0}$ berlaku

$$
\left\|x_{n}-x_{m}\right\|<\varepsilon .
$$

Setiap barisan yang konvergen merupakan barisan Cauchy, akan tetapi kebalikannya belum tentu berlaku. 
Teorema 2.4 Diberikan ruang bernorma $(X,\|\cdot\|)$. Setiap barisan $\left(x_{n}\right) \subset X$ konvergen adalah barisan Cauchy.

Bukti: Diketahui barisan $\left(x_{n}\right) \subset X$ konvergen, berarti ada $x \in X$ sehingga

$$
\lim _{n \rightarrow \infty}\left\|x_{n}-x\right\|=0 \text {. }
$$

Ekuivalen untuk setiap bilangan $\varepsilon>0$ terdapat $n_{0} \in N$ sehingga

$$
\left\|x_{n}-x\right\|<\frac{\varepsilon}{2}
$$

untuk setiap $n \geq n_{0}$.

Jadi, untuk setiap $n, m \geq n_{0}$ diperoleh

$$
\left\|x_{m}-x_{n}\right\| \leq\left\|x_{m}-x\right\|+\left\|x_{n}-x\right\|<\varepsilon .
$$

Jadi, $\left(x_{n}\right) \subset X$ merupakan barisan Cauchy.

Teorema 4.2 menjamin bahwa setiap barisan konvergen merupakan barisan Cauchy, akan tetapi kebalikannya blum tentu, yaitu setiap barisan Cauchy belum tentu merupakan barisan konvergen.

Teorema 2.5 Diberikan ruang bernorma $(X,\|\cdot\|)$. Jika suatu barisan Cauchy di dalam $X$ mempunyai sub-barisan yang konvergen, maka barisan Cauchy tersebut juga konvergen.

Bukti: lihat referensi [5].

Setiap barisan Cauchy di dalam ruang bernorma $X$ adalah terbatas, yaitu ada bilangan riil $M \geq 0$ berlaku

$$
\left\|x_{n}\right\| \leq M
$$

untuk setiap $n \in N$.

Selanjutnya, jika setiap barisan Cauchy pada ruang bernorma $(X,\|\cdot\|)$ konvergen di $X$ maka $(X,\|\cdot\|)$ dikatakan ruang Banach, yaitu ruang bernorma yang lengkap.

\section{INTEGRAL DUNFORD}

Berikut ini diuraikan sekilas tentang integral Dunford, dibahas beberapa sifat-sifatnya lebih khusus ruang linearnya serta teorema kekonvergenen terdominasi Lebesgue yang digunakan untuk menunjukkan kelengkapan.

Definisi 3.1 [1] Diketahui X ruang Banach. Fungsi terukur lemah $f:[a, b] \rightarrow X$ disebut terintegral Dunford pada $[a, b]$, jika untuk sebarang $x^{*} \in X^{*}$ fungsi komposisi $x^{*}(f)$ terintegral Lebesgue pada $[a, b]$ dan untuk setiap himpunan terukur $E \subset[a, b]$ ada vektor $x_{(f, E)}^{* *} \in X^{* *}$ sehingga berlaku 


$$
x_{(f, E)}^{* *}\left(x^{*}\right)=(L) \int_{E} x^{*}(f),
$$

untuk setiap $x^{*} \in X^{*}$.

Fungsi $f$ yang terintegral Dunford, dinotasikan $f \in D[a, b]$.

Nilai integral Dunford $(D) \int_{E} f$, fungsi $f$ atas himpunan terukur $E \subset[a, b]$ diberikan oleh $x_{(f, E)}^{* *} \in X^{* *}$, yaitu

$$
x_{(f, E)}^{* *}=(D) \int_{E} f,
$$

adalah tunggal.

Teorema $3.2[6]$ Jika $f \in D[a, b]$, maka untuk setiap $E \subset[a, b]$ himpunan terukur $x_{(f, E)}^{* *} \in X^{* *}$ tunggal.

Beberapa fungsi seperti fungsi konstan, fungsi kontinu, fungsi yang terintegral Riemann, terintegral Lebesgue, atau fungsi yang terintegral McShane adalah terintegral Dunford.

Teorema 3.3 Fungsi $f \in D[a, b]$ jika dan hanya jika untuk sebarang $x^{*} \in X^{*}, x^{*} f \in L[a, b]$.

Bukti: Jelas menurut Definisi.

Berdasarkan Definisi 3.1 dan Teorema 3.3, maka himpunan fungsi-fungsi yang mana terintegral Dunford adalah ruang linear.

Teorema $3.4[8]$ Himpunan $D[a, b]$ merupakan ruang linear.

Bukti: Koleksi $D[a, b]$ dikatakan ruang linear jika untuk setiap dua fungsi $f, g \in D[a, b]$ dan sebarang skalar $u \in R$ maka berlaku $f+g \in D[a, b]$ (additive) dan $u f \in D[a, b]$ (homogenous). Diambil sebarang dua fungsi $f, g \in D[a, b]$ dan sebarang skalar $u \in R$. Diketahui $f, g \in D[a, b]$, menurut Teorema 3.3 maka untuk setiap $x^{*} \in X^{*}$ diperoleh bahwa $x^{*} f \in L[a, b]$ dan $x^{*} g \in L[a, b]$. Karena ruang fungsi terintegral Lebesgue merupakan ruang linear, maka untuk sebarang $x^{*} \in X^{*}$ benar bahwa $x^{*}(f+g) \in L[a, b]$. Artinya $f+g \in D[a, b]$. Untuk sebarang skalar $u \in R$ dan untuk sebarang $x^{*} \in X^{*}$ benar bahwa $x^{*}(u f) \in L[a, b]$. Artinya $u f \in D[a, b]$.

Jadi, $D[a, b]$ ruang linier.

Teorema 3.5 Fungsi $f=\theta$ hampir dimana-mana pada $[a, b]$ merupakan fungsi terintegral Dunford dan jika $E \subset[a, b]$ himpunan terukur maka

$$
x_{(f, E)}^{* *}=\theta \text {. }
$$


Bukti: Karena $f=\theta$ hampir dimana-mana pada $[a, b]$, maka ada himpunan terukur $E \subset[a, b]$ dengan $\mu_{\alpha}(E)=0$ dan jika $x^{*} \in X^{*}$ maka

$$
x^{*} f(x)=0, x \in[a, b]-E \text { dan } x^{*} f(x) \neq 0, x \in E .
$$

Dibentuk $\quad E=\bigcup_{k=1}^{\infty} E_{k} \quad$ dengan $\quad E_{k}=\{x \in E: k-1 \leq\|f(x)\| \leq k, k=1,2,3, \ldots\} \subset E \quad$ dan $\mu_{\alpha}\left(E_{k}\right)=0$. Diambil sebarang $\varepsilon>0$, maka untuk suatu $k$ terdapat himpunan terbuka $O_{k}$ dengan $\mu_{\alpha}\left(O_{k}\right)<\frac{\varepsilon}{k 2^{k}}$ sehingga $O_{k} \supset E_{k}$. Didefinisikan fungsi $\delta$ positif pada $[a, b]$ di mana $N(x, \delta(x)) \subset O_{k}$ untuk setiap $x \in E_{k}, k=1,2,3, \ldots$ dan sebarang fungsi $\delta$ positif untuk $x$ yang lainnya. Jika $E \subset[a, b]$ himpunan terukur maka berlaku

$$
\left|\int_{E} x^{*}(f)-0\right|=\left|\int_{x \in E_{k}} x^{*} f(x)+\int_{x \notin E_{k}} x^{*} f(x)\right|=\left|\int_{x \in E_{k}} x^{*} f(x)\right|<\sum_{k=1}^{\infty}\left\|x^{*}\right\| k \frac{\varepsilon}{2^{k} k}=\varepsilon
$$

untuk setiap $x^{*} \in X^{*}$ dan $\left\|x^{*}\right\| \leq 1$. Hal ini berarti $x^{*} f \in L[a, b]$. Lebih lanjut jika $E \subset[a, b]$ himpunan terukur ada vektor $x_{(f, E)}^{* *} \in X^{* *}$ benar bahwa

$$
x_{(f, E)}^{* *}\left(x^{*}\right)=(L) \int_{A} x^{*} f=0 .
$$

Jadi $f \in D[a, b]$ dan $x_{(f, E)}^{* *}=\theta$.

Diberikan teorema kekonvergenan terdominasi Lebesgue yang akan digunakan untuk menunjukkan kelengkapan ruang bernorma atas operator linear dan terbatas.

Teorema 3.6 (Teorema Kekonvergenan Terdominasi Lebesgue) Diketahui fungsi $f:[a, b] \rightarrow X$, fungsi $g:[a, b] \rightarrow X$ dan fungsi $f_{n}:[a, b] \rightarrow X$ untuk setiap $n \in N$ serta $g \in D[a, b]$ dan $f_{n} \in D[a, b]$ untuk setiap $n \in N$. Jika barisan fungsi $\left(f_{n}\right)$ adalah konvergen lemah ke fungsi $f$ pada $[a, b]$ dan $\left|x^{*} f_{n}(x)\right| \leq x^{*} g(x)$ untuk setiap $n \in N$, $x^{*} \in X^{*} \quad x \in[a, b]$, maka $f \in D[a, b]$ dan

$$
x_{(f, E)}^{* *}\left(x^{*}\right)=\lim _{n \rightarrow \infty} x_{\left(f_{n}, E\right)}^{* *}\left(x^{*}\right)
$$

untuk setiap $E \subset[a, b]$ himpunan terukur.

Bukti: Diberikan $E \subset[a, b]$ sebarang himpunan terukur.

Karena $\left(f_{n}\right)$ adalah konvergen lemah ke fungsi $f$ pada $[a, b]$, maka untuk setiap $x^{*} \in X^{*}$ barisan fungsi $\left(x^{*} f_{n}\right)$ konvergen ke $x^{*} f$, yaitu untuk setiap $\varepsilon>0, x \in[a, b]$, dan setiap $x^{*} \in X^{*}$ ada bilangan asli $n_{0}=n_{0}\left(\varepsilon, x^{*}, x\right)$ sehingga jika $n \geq n_{0}$ benar bahwa

$$
\left|x^{*} f_{n}(x)-x^{*} f(x)\right|<\varepsilon \text {. }
$$

Hal ini berarti 


$$
x^{*} f_{n}(x)-\varepsilon<x^{*} f(x)<x^{*} f_{n}(x)+\varepsilon .
$$

Karena

$$
\left|x^{*} f_{n}(x)\right| \leq x^{*} g(x) \Leftrightarrow-x^{*} g(x) \leq x^{*} f_{n}(x) \leq x^{*} g(x),
$$

maka

$$
x^{*} g(x)-x^{*} f_{n}(x)=x^{*}\left(g-f_{n}\right)(x) \geq 0 .
$$

Akibatnya $\left(x^{*}\left(g-f_{n}\right)\right)$ konvergen ke $x^{*}(g-f)$ pada $[a, b]$, yaitu barisan fungsi $\left(g-f_{n}\right)$ konvergen lemah ke $g-f$ pada $[a, b]$.

Hal ini berakibat bahwa barisan $\left((L) \int_{E} x^{*}\left(g-f_{n}\right)\right)$ merupakan barisan terbatas untuk setiap $n$ dan $x^{*} \in X^{*}$. Berdasarkan Lemma Fatou diperoleh $g-f \in D[a, b]$ dan

$$
x_{(g-f, E)}^{* *}\left(x^{*}\right) \leq \liminf _{n \rightarrow \infty} x_{\left(g-f_{n}, E\right)}^{* *}\left(x^{*}\right) \text {. }
$$

Oleh karena $-x^{*} g(x) \leq x^{*} f(x) \leq x^{*} g(x)$ untuk setiap $x \in E \subset[a, b]$ dan $x^{*} \in X^{*}$ dan diketahui bahwa $g \in D[a, b]$, maka $f \in D[a, b]$.

Lebih lanjut

$$
\begin{aligned}
0 & \leq x_{(g, E)}^{* *}\left(x^{*}\right)-x_{(f, E)}^{* *}\left(x^{*}\right)=x_{(g-f, E)}^{* *}\left(x^{*}\right) \\
& \leq \lim _{n \rightarrow \infty} \inf x_{\left(g-f_{n}, E\right)}^{* *}\left(x^{*}\right) \\
& =\lim _{n \rightarrow \infty} \inf (L) \int_{E} x^{*} g+\lim _{n \rightarrow \infty} \inf (L) \int_{E} x^{*}\left(-f_{n}\right) \\
& =(L) \int_{E} x^{*} g-\lim _{n \rightarrow \infty} \sup (L) \int_{E} x^{*} f_{n} \\
& =x_{(g, E)}^{* *}\left(x^{*}\right)-\lim _{n \rightarrow \infty} \sup x_{\left(f_{n}, E\right)}^{* *}\left(x^{*}\right)
\end{aligned}
$$

Didapat

$$
\lim _{n \rightarrow \infty} \sup x_{\left(f_{n}, E\right)}^{* *}\left(x^{*}\right) \leq x_{(f, E)}^{* *}\left(x^{*}\right) .
$$

Karena

$$
x^{*} g(x)+x^{*} f_{n}(x)=x^{*}\left(g+f_{n}\right)(x) \geq 0,
$$

Maka berakibat barisan fungsi $\left(x^{*}\left(g+f_{n}\right)\right)$ konvergen ke fungsi $x^{*}(g+f)$ pada $[a, b]$. Jadi, barisan $\left((L) \int_{E} x^{*}\left(g+f_{n}\right)\right)$ adalah terbatas untuk setiap $n$ dan $x^{*} \in X^{*}$.

Berdasarkan Lemma Fatou diperoleh $g+f \in D[a, b]$ dan

$$
x_{(g+f, E)}^{* *}\left(x^{*}\right) \leq \liminf _{n \rightarrow \infty} x_{\left(g+f_{n}, E\right)}^{* *}\left(x^{*}\right) .
$$

Oleh karena itu

$$
\begin{aligned}
0 & \leq x_{(g, E)}^{* *}\left(x^{*}\right)+x_{(f, E)}^{* *}\left(x^{*}\right)=x_{(g+f, E)}^{* *}\left(x^{*}\right) \\
& \leq \lim _{n \rightarrow \infty} \inf x_{\left(g+f_{n}, E\right)}^{* *}\left(x^{*}\right)
\end{aligned}
$$




$$
\begin{aligned}
& =\lim _{n \rightarrow \infty} \inf (L) \int_{E} x^{*} g+\liminf _{n \rightarrow \infty}(L) \int_{E} x^{*} f_{n} \\
& =(L) \int_{E} x^{*} g+\liminf _{n \rightarrow \infty}(L) \int_{E} x^{*} f_{n} \\
& =x_{(g, E)}^{* *}\left(x^{*}\right)+\lim _{n \rightarrow \infty} \inf x_{\left(f_{n}, E\right)}^{* *}\left(x^{*}\right)
\end{aligned}
$$

Didapat

$$
\lim _{n \rightarrow \infty} \inf x_{\left(f_{n}, E\right)}^{* *}\left(x^{*}\right) \geq x_{(f, E)}^{* *}\left(x^{*}\right)
$$

Jadi,

$$
\lim _{n \rightarrow \infty} \sup x_{\left(f_{n}, E\right)}^{* *}\left(x^{*}\right) \leq x_{(f, E)}^{* *}\left(x^{*}\right) \leq \lim _{n \rightarrow \infty} \inf x_{\left(f_{n}, E\right)}^{* *}\left(x^{*}\right) \Leftrightarrow x_{(f, E)}^{* *}\left(x^{*}\right)=\lim _{n \rightarrow \infty} x_{\left(f_{n}, E\right)}^{* *}\left(x^{*}\right) .
$$

\section{RUANG BANACH ATAS NORMA OPERATOR}

Fungsi $f$ dan $g$ dikatakan ekuivalen, jika $f=g$ hampir dimana-mana pada $[a, b]$, yaitu jika terdapat himpunan terukur- $\alpha E \subset[a, b]$ dengan $\mu_{\alpha}(E)=0$ sehingga

$$
f(x)=g(x)
$$

untuk setiap $x \in[a, b]-E$. Menurut hasil kajian untuk suatu fungsi $f$ terintegral Dunford, operator $T: X^{*} \rightarrow L_{1}$ oleh

$$
T\left(x^{*}\right)=x^{*}(f) \text {, }
$$

untuk sebarang $x^{*} \in X^{*}$ merupakan operator linear dan terbatas. Sedangkan himpunan operator-operator linear dan terbatas $T: X^{*} \rightarrow L_{1}$ yang dinotasikan dengan $B\left(X^{*}, L_{1}\right)$ merupakan ruang linear. Selanjutnya telah diperlihatkan juga bahwa, terhadap norma operator

$$
\begin{gathered}
\|T\|=\sup \left\{\left\|T x^{*}\right\|: x^{*} \in X^{*},\left\|x^{*}\right\|=1\right\} \\
=\sup \left\{\left\|x^{*} f\right\|: x^{*} \in X^{*},\left\|x^{*}\right\|=1, f \in D[a, b]\right\}, \\
\left(B\left(X^{*}, L_{1}\right),\|\cdot\|\right) \text { merupakan ruang bernorma [8]. }
\end{gathered}
$$

Teorema 4.1 $B\left(X^{*}, L_{1}\right)$ merupakan ruang bernorma yang lengkap.

Bukti: Diambil sebarang $\left(T_{n}\right) \subset B\left(X^{*}, L_{1}\right)$ barisan Cauchy, yaitu untuk sebarang $\varepsilon>0$ terdapat bilangan asli $n_{0}$ sedemikian untuk setiap bilangan asli $m, n \geq n_{0}$ berlaku

$$
\left\|T_{n}-T_{m}\right\|<\frac{\varepsilon}{3}
$$

Jadi, untuk setiap $x^{*} \in X^{*}$ berlaku

$$
\left\|T_{n}-T_{m}\right\|=\sup \left\{\left\|x^{*} f_{n}-x^{*} f_{m}\right\|: x^{*} \in X^{*},\left\|x^{*}\right\|=1, f_{n}, f_{m} \in D[a, b], n=1,2,3, \ldots\right\}<\frac{\varepsilon}{3} .
$$

Hal ini berakibat

$$
\left\|x^{*} f_{n}-x^{*} f_{m}\right\|<\frac{\varepsilon}{3}
$$


untuk setiap $x^{*} \in X^{*}$. Jadi, $\left(x^{*} f_{n}\right)$ barisan Cauchy di $L_{1}$. Karena $L_{1}$ lengkap, maka barisan Cauchy $\left(x^{*} f_{n}\right)$ konvergen di $L_{1}$. Katakan konvergen ke $F \in L_{1}$. Karena $x^{*} f_{n} \in L_{1}$, untuk setiap bilangan asli $n$ maka $f_{n} \in D[a, b]$ dan karena barisan $\left(x^{*} f_{n}\right)$ konvergen untuk setiap $x^{*} \in X^{*}$ maka barisan $\left(f_{n}\right)$ konvergen lemah.

Selanjutnya karena $T_{n}$ terbatas, maka terdapat bilangan riil $c \geq 0$ sehingga untuk setiap $x^{*} \in X^{*}$ berlaku

$$
\left\|x^{*} f_{n}\right\|=\left\|T_{n}\left(x^{*}\right)\right\| \leq c,
$$

untuk setiap bilangan asli $n$.

Untuk setiap $x^{*} \in X^{*}$, dibentuk

$$
T\left(x^{*}\right)(x)=x^{*} g(x)=c,
$$

untuk setiap $x \in E \subset[a, b]$ himpunan terukur dan suatu $g \in D[a, b]$.

Diperoleh $x^{*} g=c \in L_{1}$ dan $g \in D[a, b]$

Jadi, untuk setiap $x^{*} \in X^{*}$ berlaku,

$$
\left\|x^{*} f_{n}\right\|=\left\|T_{n}\left(x^{*}\right)\right\| \leq c=T\left(x^{*}\right)=x^{*} g \text {. }
$$

Karena $\left(f_{n}\right)$ konvergen lemah dan $\left\|x^{*} f_{n}\right\| \leq x^{*} g$ untuk setiap $x^{*} \in X^{*}$ dan suatu $g \in D[a, b]$, maka menurut Teorema Kekonvergenan Terdominasi Lebesgue diperoleh bahwa $F=x^{*} f \in L_{1}$, yaitu $f \in D[a, b]$.

Jadi, $B\left(X^{*}, L_{1}\right)$ lengkap.

\section{KESIMPULAN}

Koleksi operator-operator linear dan terbatas dari ruang dual ke ruang fungsi terintegral Lebesgue merupakan ruang linear. Kemudian terhadap norma operator seperti definisi merupakan ruang bernorma. Lebih lanjut ruang bernorma tersebut merupakan ruang bernorma yang lengkap.

\section{REFERENSI}

[1] Schwabik, S., Guoju, Ye., Topics in Banach Space Integration, World Scientific, Singapore, 2005.

[2] Guoju, Ye., Tianqing, An., "On Henstock-Dunford and Henstock-Pettis Integrals," IJMMS, 25(7): 467-478, 2001.

[3] Saifullah, Integral Henstock-Dunford pada Ruang Euclide $R^{n}$, Tesis, Departemen Matematika Fakultas MIPA, Universitas Gadjah Mada, Yogyakarta, 2003.

[4] Kreyszig, E., Introductory Funtional Analysis with Applications, John Willey \& Sons, USA, 1989.

[5] Darmawijaya, S., Pengantar Analisis Abstrak, Jurusan Matematika Fakultas MIPA Universitas Gadjah Mada, Yogyakarta, 2007. 
[6] Solikhin, Sumanto, Aziz, A., \& Hariyanto, S., "Operator pada Ruang Fungsi Terintegral Dunford," Journal of Fundamental Mathematics and Application (JFMA), 2(1): 110, 2018. DOI: 10.14710/jfma.v1i2.17

[7] Solikhin, Hariyanto, S., "Sumanto, \& Aziz, A., Operator Adjoint pada Ruang Fungsi Terintegral Dunford," PRISMA Prosiding Seminar Nasional Matematika, 3, 34-40: 2020. Link: https://journal.unnes.ac.id/sju/index.php/prisma/article/view/37545.

[8] Solikhin, Hariyanto, S., Sumanto, \& Aziz, A., "Norma Operator pada Ruang Fungsi Terintegral Dunford," Journal of Fundamental Mathematics and Application (JFMA), 2(2): 2019. DOI: http://dx.doi.org/10.14710/jfma.v2i2.42 